\title{
DESABAMENTO DO PORTO DE SANTANA-AP EM MARÇO DE 2013: PERSPECTIVAS DE UM IMPACTO SOCIOAMBIENTAL SOBRE O RIO AMAZONAS, BRASIL
}

\section{ARTIGO ORIGINAL}

SOUZA, Keulle Oliveira da ${ }^{1}$

SILVA, Inailza Barata ${ }^{2}$

CORDEIRO, Nadabe de Jesus da Silva ${ }^{3}$

NETO, Lúcio Osvaldo Rabelo Mendes ${ }^{4}$

MACÊDO, Jucimeire Rocha ${ }^{5}$

MOREIRA, Elisângela Claudia de Medeiros ${ }^{6}$

\footnotetext{
${ }^{1}$ Mestranda em Estudos Antrópicos na Amazônia-PPGEAA, na Universidade Federal do Pará - UFPA, Campus Castanhal.
}

${ }^{2}$ Especialista em Planejamento e Orçamento Público. Docente na Universidade UNIP/AP.

${ }^{3}$ Especialista em Planejamento e Orçamento Público. Docente na Universidade UNIP/AP.

${ }^{4}$ Agrônomo. Professor. Pesquisador na Associação em Áreas de Assentamento no Estado do Maranhão - ASSEMA.

${ }^{5}$ Mestre em Estudos Antrópicos na Amazônia. Docente da Rede de Ensino do Município de Mãe do Rio/PA.

${ }^{6}$ Mestre em Teoria e Pesquisa do Comportamento. Docente e Pesquisadora da Universidade do Estado do Pará - UEPA. Doutoranda em Doenças Tropicais na Universidade Federal do Pará - NMT/UFPA. 
DENDASCK, Carla Viana ${ }^{7}$

MORAES, Jones Souza ${ }^{8}$

RAMOS, João Batista Santiago ${ }^{9}$

SILVA, Iracely Rodrigues da ${ }^{10}$

OLIVEIRA, Euzébio de ${ }^{11}$

SOUZA, Keulle Oliveira da. SILVA, Inailza Barata. Et al. Desabamento do porto de Santana-AP em março de 2013: Perspectivas de um impacto socioambiental sobre o Rio Amazonas, Brasil. Revista Científica Multidisciplinar Núcleo do Conhecimento. Ano 04, Ed. 12, Vol. 05, pp. 48-64. Dezembro de 2019. ISSN: 24480959, Link de acesso: https://www.nucleodoconhecimento.com.br/meioambiente/desabamento-do-porto-de-santana-ap

\section{RESUMO}

O presente artigo consiste numa análise do desabamento do Porto de exportação de minério de ferro, situado no município de Santana/AP, ocorrido em março de 2013, e

7 Teóloga. Doutora em Psicanálise Clínica. Pesquisadora do Centro de Pesquisa e Estudos Avançados, São Paulo, SP.

${ }^{8}$ Mestrando em Estudos Antrópicos na Amazônia-PPGEAA, na Universidade Federal do Pará - UFPA, Campus Castanhal.

9 Doutor em Filosofia e Ciências da Educação. Docente e Pesquisador da Universidade Federal do Pará - UFPA, Campus Castanhal.

10 Doutora em Recursos Ambientais Amazônicos. Docente e Pesquisadora da Universidade Federal do Pará - UFPA, Campus de Bragança.

${ }^{11}$ Doutor em Medicina/Doenças Tropicais. Docente e Pesquisador da Universidade Federal do Pará - UFPA. Pesquisador Colaborador do Núcleo de Medicina Tropical NMT/UFPA. 
suas consequências, em destaque para as sociais e ambientais. Com bases nesses aspectos, este artigo objetivou analisar quais foram e ainda são as implicações de um impacto socioambiental sobre o Rio Amazonas, passados seis anos desde o desabamento do Porto de Santana-AP. Metodologicamente realizou-se um estudo de abordagem qualitativa, de caráter descritivo-analítico e exploratório, desenvolvido por meio de uma pesquisa de revisão bibliográfica, acerca da literatura publicada em livros, artigos científicos publicados em periódicos, bem como, análise de documentos oficiais e relatórios, relativos aos estudos sobre o desastre. Uma nova fase de exploração mineral foi desencadeada no Estado do Amapá nas décadas iniciais do século XXI. Nesse contexto, os municípios de Santana e Pedra Branca do Amapari, foram e ainda são cidades estratégicas para o funcionamento da dinâmica da exploração mineral no Estado. O desabamento da estrutura portuária matou seis pessoas, derramou uma alta quantidade de minério de ferro sobre o Rio Amazonas, afetando diretamente as características ambientais do Rio, bem como o modo de vida de comunidades que dependem deste, pois esses povos possuem relações culturais de utilidade e sobrevivência diretas com o mesmo. A longo prazo, o desastre afetou a economia mineral amapaense, causou demissões em massa, falência de muitas prestadoras de serviços, dentre outros. Diante das fragilidades evidenciadas e agravados a partir do desabamento do Porto de Santana, conclui-se que é imprescindível a reformatação das políticas de planejamento urbano-territoriais que invistam, deste a instalação desses empreendimentos, até na prevenção e alertas de possíveis desastres, sobretudo em regiões que sediam grandes projetos minerais, tais como o caso em estudo.

Palavras-chaves: Porto de Santana, Impacto socioambiental, Rio Amazonas, Brasil.

\section{INTRODUÇÃO}

A Amazônia brasileira possui reservas minerais, de grandes interesses e utilidades mundiais, pois é detentora de substâncias metálicas como ferro, manganês, nióbio, cobre, alumínio, dentre outros, que movimentam substancialmente a indústria mineral nacional e mundial. Avanços e descobertas científicas neste setor mostraram o grande 
potencial de exploração destes minerais em solo brasileiro, bem como os seus impactos positivos na economia nacional e mundial decorrentes dessa atividade (AGÊNCIA NACIONAL DE MINERAÇÃO, 2019; CANTO, 2016).

Segundo dados divulgados pela Agência Nacional de Mineração (ANM), referentes ao Anuário Mineral Brasileiro de 2018, na região Norte do Brasil, os Estados do Pará, Amapá, Rondônia e Amazonas foram os que mais se destacaram na, extração, produção e comercialização mineral. No ano de 2017, Pará e Amapá corresponderam juntos a $43,25 \%$ das participações no valor da produção mineral comercializada no País, com base na extração de substâncias metálicas na Amazônia brasileira (AGÊNCIA NACIONAL DE MINERAÇÃO, 2019).

Nas primeiras décadas do século XXI, no Amapá, a instalação da Mineração Pedra Branca do Amapari (MPBA), vendida no ano de 2010 para o grupo australiano Beadell Resources Limited (BRL), e da Mineração e Metálicos S.A (MMX), vendida à Anglo American e posteriormente à Zamin Ferrous (ZM), representaram uma nova fase de exploração mineral no Estado do Amapá (RIBEIRO, SILVA 2010), no contexto da gestão ambiental e de um Estado consolidado, motivado pela lógica comercial do mercado internacional (CHAGAS, 2013). Esses empreendimentos minerais em seus novos arranjos, se destacam na exploração de ouro e ferro na região da antiga INDÚSTRIA e COMÉRCIO S.A (ICOMI), sendo o primeiro projeto de exploração mineral industrial da Amazônia brasileira, situado em Serra do Navio/AP.

$\mathrm{Na}$ dinâmica do setor minerário amapaense, os municípios de Pedra Branca do Amapari (PBA) e SANTANA tem uma função estratégica e necessária para o funcionamento da indústria mineral. PBA por sediar minas de grandes empreendimentos, e Santana é a cidade onde se localizam os portos, utilizados para o escoamento, estocagem e exportações de minérios.

Em março do ano de 2013, o Porto de exportação de minério de ferro, utilizado pela empresa Anglo American, situado no município de Santana/AP desabou, por causas inconclusivas e conflituosas, até então. O desastre na cidade de Santana, que fica a 
vinte quilômetros da capital Macapá, matou seis funcionários (dois corpos nunca foram encontrados), derramou grande quantidade de minério de ferro e parte da estrutura administrativa da empresa, sobre o Rio Amazonas e gerou (e ainda gera) instabilidades sociais, econômicas e ambientais para aquele município, para Pedra Branca do Amapari/AP e para a sociedade amapaense de modo geral, mesmo que direta ou indiretamente, acarretando disputas judiciais que vão desde à recuperação ambiental, à indenização das famílias das vítimas, e uma série de divergências que não se esgotam, devido à complexidade do evento extremo, ocorrido no contexto amazônico, relacionado à atividade mineradora, evidenciando assim, potencialidades e fragilidades no planejamento dos processos que envolvem a implantação dos empreendimentos e a exploração mineral no Estado Amapá.

É válido ressaltar, que "não se pode assumir, que todas as tensões que envolvam recursos naturais, resultem em conflitos ambientais" (BRITO et al., 2011, p. 58). O que faz um conflito ser caracterizado como socioambiental é a reunião de diversos fatores, sejam eles relacionados à falta de um determinado recurso, refletindo em questões econômicas e possíveis alterações sociais provocadas por ele, abalos em instituições sociais, que apenas se definem como tal, pela capacidade de gerar convulsões ou desequilíbrios ambientais decorrentes de ações antrópicas (LIBISZEWSKI, 1992; BRITO et al., 2011).

Com base nesses aspectos, compreender o fenômeno desastre, como o desabamento do Porto de Santana/AP permite a aproximação de várias áreas do conhecimento, dentre elas as ambientais ligadas diretamente às ciências sociais. Grupos sociais (famílias das vítimas e empresas) construíram as suas perspectivas assimétricas sobre aquele evento extremo, sem a devida atenção do fato ocorrido, associado ao contexto mineral desenvolvido no Estado do Amapá.

Interpretações científicas isoladas que dissociam o homem da natureza e enfatizam dualidades entre sociedade-natureza, se mostram frágeis para as análises de fenômenos complexos relacionados aos modelos de desenvolvimento e às formas como o homem estabelece a sua relação com o ambiente. Fenômenos como 
desastres, sejam eles naturais ou não, exigem reformulações epistemológicas e conceituais, que refletem os limites da ciência moderna.

Na contramão desse pensamento, Carvalho e Steil (2014) destacam as formulações de possíveis "Epistemologias Ecológicas", com o objetivo de provocar interpretações novas, desafiando conceitos hegemônicos. Para os autores "nosso modo de habitar o planeta não está separado do nosso modo de conhecê-lo. Esta indissociabilidade destes dois modos torna plausível fazer uma releitura de um conjunto de autores contemporâneos [...]" (CARVALHO; STEIL, 2014, p. 163).

Dada a magnitude do objeto de pesquisa em questão, é necessário estabelecer conexões entre os diversos campos disciplinares, que permitam relações orgânicas entre saberes acadêmicos, profissionais (civis e militares) e populares (VALENCIO, 2009), principalmente na ocorrência de desastres relacionados à mineração na Amazônia, onde o foco das discussões, acabam sendo em relação a fala de técnicos e a divulgação de números (de vítimas, de custos para indenizações, recuperação, sempre voltados para valores monetários), porém deixam sérias lacunas, no que se refere aos impactos socioambientais decorrentes desses desastres, que inclusive existem inúmeras pessoas e comunidades que dependem do Rio Amazonas, como neste caso, para a sua sobrevivência.

Desse modo, com base nos estudos de (OLIVER-SMITH, 1995; QUARANTELLI, 1998; GILBERT, 1998; QUARANTELLI, 2005; RIPLEY, 2008; MARCHEZINI, 2009; VALÊNCIO, 2009; ULLBERG, 2017; MARCHEZINI, 2018), discutiremos a agenda científica, que vem se consolidando no campo dos desastres, que contribuem para a análise das perspectivas de grupos sociais envolvidos nestas tragédias, tais como: famílias das vítimas, poder público, empresas, órgãos de fiscalização e regulamentação ambiental, dentre outros.

Diante os fatos discorridos até aqui, a presente pesquisa justifica-se pelos conflitos que foram agravados e provocados no Estado do Amapá, a partir do desabamento do Porto de Santana, de uso privativo, ocorrido no ano de 2013, operacionalizado na 
época pela empresa mineradora multinacional Anglo American (antecessora da Zamin Ferrous), desastre esse associado diretamente a perspectivas da ocorrência de um impacto socioambiental de grandes proporções sobre o Rio Amazonas. Com base nesse contexto, o presente estudo objetivou analisar quais foram e ainda são as implicações de um impacto socioambiental sobre o Rio Amazonas, passados seis anos desde o desabamento do Porto de Santana-AP.

\section{METODOLOGIA}

O presente trabalho foi realizado por meio da abordagem qualitativa, de caráter descritivo-analítico e exploratório, desenvolvido por meio de uma revisão bibliográfica acerca da literatura publicada em livros, artigos científicos publicados em periódicos, bem como, da análise de documentos oficiais e relatórios, relativos ao tema em estudo. Nessa pesquisa, buscou-se analisar, de maneira imparcial, a realidade dos fatos relativos ao do tema em questão, destacando-se os principais autores que discutem os grandes projetos, com destaque aos relativos à mineração na região da Amazônia brasileira, e analisam o fenômeno dos desastres.

É de caráter descritivo-analítico, posto que buscou classificar, descrever, explicar e esclarecer o problema apresentado. É, também, uma pesquisa exploratória, pois objetivou pesquisar, analisar e descrever as ideias principais dos autores, através das informações pesquisadas e publicadas pelos mesmos, referentes o tema em foco.

\subsection{LOCUS DO ESTUDO}

Santana é o segundo maior município do Estado do Amapá, com população estimada em 121.364 pessoas (IBGE, 2019). As ocupações na região do município remontam o século XVI, a partir de um Agrupamento Militar na Ilha de Santana, localizada à margem esquerda do Rio Amazonas. Mas foi a partir da descoberta de manganês no município de Serra do Navio/AP, ainda na metade do século XX que Santana, por ser um município portuário, recebeu um aumento populacional significativo, em função da abertura da Ferrovia "Santana-Serra do Navio" criada com o objetivo de atender as 
demandas operacionais de escoamento do minério extraído na região, bem como para transportar operários ligados a essa atividade (MORAIS, 2011).

O município de Santana ainda mantém uma relação direta com a indústria mineral no Amapá. Em 2005, a Mineração e Metálicos S.A. (MMX) passou a utilizar parte significativa da estrutura construída pela empresa ICOMI, ao longo dos 40 anos de atividades no Estado do Amapá, como: o terminal portuário, que desabou em 2013, e a Estrada de Ferro Amapá (EFA), que liga Santana aos municípios de PBA e Serra do Navio (MORAIS; MORAIS, 2011).

\section{RESULTADOS E DISCUSSÃO}

O fenômeno "desastre" é uma arena fértil para as pesquisas científicas, construção de análises técnicas, interpretações não oficiais, divulgação de notícias e imagens pela mídia, para gerar momentos de solidariedade, demonstrar diferenças e indiferenças envolvidas no sinistro. Tradicionalmente, o foco dos desastres direcionou-se para a naturalização (ameaça natural) ou para solução dos problemas evidenciados por eles, isolando-os do contexto social. No campo das ciências sociais existe uma pluralidade de interpretações sobre o termo, mas também atualmente existem "convergências interpretativas e complementariedades interessantes no debate em torno da definição do que seja um desastre" (VALÊNCIO; VALÊNCIO, 2017, p. 3), que levantam questões críticas para através da inserção da dimensão social nas análises dos sinistros ocorridos.

Brevemente serão destacados alguns estudos sistematizados na área dos desastres que remontam o início do século XX. Em 1917, no Canadá, mais precisamente no Porto Guerra de Halifax, na cidade de Halifax, houve um choque entre navios carregados de munições, que abasteciam a indústria da Primeira Guerra Mundial. A colisão entre os navios atingiu milhares de pessoas, deixando vários mortos e desabrigados (QUARANTELLI, 1998; MARCHEZINI, 2009).

O desastre no Porto Guerra de Halifax, completou o seu centenário em dezembro do ano de 2017, e é reconhecidamente até hoje como sendo "a maior explosão da era 
pré-atômica provocada pela colisão de dois navios" (MUSEU MARÍTIMO, 2017). Na década de 1920, foi publicado o livro de Samuel Henry Prince "Catástrofe e Mudança Social" baseado em um estudo sociológico do desastre de Halifax. Para Ripley (2008), o trabalho de Prince (1920) se tornou um marco nos estudos sociológicos sobre desastres e catástrofes, porque o autor escreveu para além dos desastres, relacionando-os aos contextos sociais nos quais eles se inseriam.

As análises sobre desastres mantiveram-se tímidas até a década de 1950. Após a Segunda Grande Guerra Mundial, houve uma produção circular na área, focadas em análises comportamentais e perceptivas, impulsionados pelo contexto da Guerra Fria, pois "uma nova multidão de ansiedades a respeito de como as massas poderiam vir a reagir a ataques nucleares" (RIPLEY 2008, p. 12). Nesse momento destacou-se um modelo interpretativo de desastres baseado na reação das pessoas a forças exógenas ou fatos externos à comunidade, como um ataque aéreo (GILBERT, 1998; QUARANTELLI, 1998; MARCHEZINI, 2009).

$\mathrm{Na}$ abrangência da antropologia, ainda na metade do século $\mathrm{XX}$, referenciam-se os trabalhos de Cyril Belshaw e Felix Keesing (1951) e de Anthony Wallace (1956), os dois primeiros autores analisaram formas de adaptação do povo OROKAIVA às erupções do Monte Lamington no ano de 1951, o terceiro autor, por sua vez demonstrou forte engajamento com o tema desastres, propondo relações entre a antropologia cultural e a psicologia social (MARCHEZINI, 2018).

Na década de 1970, o antropólogo Anthony Oliver-Smith realizou pesquisas após o terremoto que destruiu a cidade de peruana Yungay naquele ano, relacionando o risco "natural" ao contexto socioeconômico do mesmo. Oliver-Smith (1995) considerando como contexto os 500 anos de colonização do Peru, destaca que:

(...) En cierto sentido, el terremoto que devastó la costa central del norte del país y sus zonas andinas, podría ser visto como un evento que empezó hace 500 años con la conquista y colonización del Perú y su consecuente inserción como colonia al sistema económico del mundo en 
desarrollo, lo cual tuvo como resultado el grave subdesarrollo de la región entera. (OLIVER-SMITH, 1995, p. 3).

A partir da década de 1970 observou-se um modelo baseado nas vulnerabilidades sociais (GILBERT, 1998). Cientistas sociais buscaram deslocar a ideia de risco e perigo como eventos excepcionais, para compreendê-los no seio da estrutura social. Neste sentido recomenda-se a leitura do conceito de Sociedade de Risco de Giddens (1991) e Beck (1997), onde riscos se tornam parte constitutiva da própria modernidade.

Os desastres também foram interpretados como incertezas geradas pelas próprias instituições, sobretudo no final dos anos 1980, nessa visão verifica-se a atuação das empresas de seguro, instituições de emergências, ou seja, os desastres são analisados a partir da relação solução-problema (MARCHEZINI, 2018).

A respeito das análises sociológicas dos desastres Mendes e Araújo (2015) afirmam que, nas primeiras análises do século $X X$, o foco da análise caminhou por vários domínios, desde aqueles atrelados às mudanças naturais e sociais, as denominadas alterações socioambientais, passando então por análises que discutem as vulnerabilidades socioambientais e a capacidade de resiliência destes, que é a capacidade de recuperação tanto social, quanto ambiental após os desastres. Chegando assim até as abordagens mais contemporâneas, relacionadas aos riscos e incertezas, respostas psicológicas de grupos sociais atingidos, processos de mobilização social, e a recuperação ambiental.

Diante desses fatos e modelos de abordagens, do que é considerado clássico nas ciências sociais e ambientais, pode-se dizer que o estudo sobre desastres é um campo em construção. Para Quarantelli (2005, p. 27) "nem todos os alunos que se interessam por desastres estão presos no século passado" e quanto mais consistentes forem os pressupostos básicos, mais coerente será a abordagem. Quanto às implicações do referido autor, o mesmo destaca que os desastres como fenômenos sociais: 
De uma certa forma, podemos dizer que o paradigma básico implícito na área dos desastres é aceitável (embora não incontestável). O paradigma atual envolve uma série de noções inter-relacionadas, mas duas das noções mais fundamentais são as seguintes: (1) os desastres são fenômenos sociais inerentemente, e (2) a origem dos desastres se encontra na estrutura social ou no sistema social. (QUARANTELLI, 2005, p. 38).

Com base nessas considerações, é possível de ampliar as discussões sobre desastres, para tratar questões que porventura não foram discutidas, mas que sugerem a instituição de novas possibilidades pesquisas e trabalhos, uma vez as razões de produção de um novo objeto de conhecimento (em qualquer campo) repassa por questões paradigmáticas e epistemológicas, e é nesse sentido que as análises sobre desastres pretendem contribuir, através do amadurecimento, fortalecimento e reformulação dos seus conceitos e modelos interpretativos. Nos domínios socio antropológicos, a compreensão de desastres centraliza-se em dinâmicas e estruturas variadas. Para Valêncio (2009, p. 5) estes campos possibilitam análises "das relações sociais, territoriais, ambientais, institucionais, historicamente produzidas".

Por meio de estudos não centralizados apenas no tempo cronológico e no espaço geográfico (que são importantes para o lócus da pesquisa), mas também no tempo e no espaço socioambiental (SOROKIN, 1942).

As análises dos desastres socioambientais até aqui discutidas permitem reflexões e questionamentos à lógica dos grandes e médios projetos desenvolvimentistas industriais na Amazônia brasileira, expressos por meio de interesses predominantemente financeiros, tanto nacionais quanto internacionais, e sobretudo carentes de estudos e interpretações que valorizem o meio ambiente e os conhecimentos e modos de vida de povos conhecidos como tradicionais da Amazônia, pois ambos são indissociáveis (DIEGUES, 2000). 
Nesta lógica contraditória de desenvolvimento, observa-se que a disputa mundial pelos recursos naturais na região da Amazônia brasileira faz com que a competição pelo controle desse território, torne-se fundamental no contexto geopolítico da Amazônia. Contudo, este modelo se contrapõe diretamente com a dinâmica populacional, econômica, cultural, política e social da região (SOUZA et al., 2019b).

No Estado do Amapá, cidades emergiram ou modificaram as suas dinâmicas para atenderem as demandas do grande capital, como a Serra do Navio/AP e Pedra Branca do Amapári/AP. Para Tostes (2011) essas e outras cidades amapaenses são em sua essência pequenas, porém expressam dilemas de grandes cidades, pois entremeiam aspectos da vida urbana e rural, formais e informais ao cruzarem modos de vida singulares e distintos.

Segundo o IBGE (2010) a cidade de PBA teve um aumento populacional de 168,72\% em dez anos, e ainda estimasse que até o final de 2019 a população atinja um total de 16.502 pessoas, obtendo uma taxa de crescimento populacional superior, inclusive, a do próprio Estado. Todavia, esse aumento populacional não veio associado a um planejamento urbanístico adequado, o que resultou na ocorrência do agravamento dos problemas urbanos e sociais já existentes, como falta de saneamento básico e abastecimento de água potável para toda a população, a coleta e o tratamento do esgoto, a limpeza urbana, o manejo correto dos resíduos sólidos, a aglomeração urbana, etc. Todas devido à explosão demográfica da cidade, decorrente do fluxo migratório intenso para o município (SOUZA et al., 2019a). No que tange ao saneamento básico e falta de água encanada, através de abastecimento público, 67,64\% das residências de PBA não dispõe desses serviços (SOUZA et al., 2019a).

Diante do exposto, o desabamento do Porto de Santana, sob a ótica de uma análise socioambiental dos desastres, não pode ser analisado como um fato isolado e unilateral, que pode ser reduzido a uma mera relação de causa e efeito. De forma direta e objetiva, a morte dos seis trabalhadores vinculados à empresa Anglo American e o derramamento de uma grande quantidade de minério de ferro sobre o Rio Amazonas ganharam destaque entre as notícias nacionais, à curto prazo, porém 
a médio e longo prazo os impactos socioambientais decorrentes desse desastre ainda são imensuráveis. Para Valêncio e Valêncio (2017), é comum nas coberturas jornalísticas de desastres a propagação de discursos técnicos, voltados para respostas rápidas ao ocorrido. Por outro lado, os autores alertam que é fundamental a compreensão das entrelinhas do fenômeno desastre, pois elas podem ser reveladoras de jogos de poder.

As estatísticas oficiais divulgadas no período pós-desastre são paulatinamente esquecidas com o passar do tempo. Para Valêncio (2009, p.5) os "desastres são cenários caóticos, permeados por tensões e busca por soluções, os que morrem, estes sim, são os que melhor dispõem do testemunho da indiferença, incapacidade, equívocos e má vontade contidos nas providências" [...].

Compreender o tempo social e ambiental do desastre possibilita discussões a longo prazo. Meia década após o desabamento do Porto, ainda é possível identificar algumas consequências e desdobramentos, a saber: no dia 12 de fevereiro de 2019, uma nova estrutura portuária flutuante da empresa Zamin Ferrous, empresa sucessora da Anglo American, tombou no mesmo lugar do desabamento do Porto em 2013. Segundo Nafes (2019) a estrutura não chegou a ser utilizada e custou o equivalente a 484 milhões de reais e o seu tombamento trouxe riscos diretos para a navegação, bem como gerou prováveis danos socioambientais no Rio Amazonas.

Além disso, de acordo com informações do Ministério Público Federal, publicadas de 5 de dezembro de 2019, tardiamente a Anglo American firmou acordo de 47 milhões de reias, para indenizar os municípios de Santana, Pedra Branca do Amapari pelos danos sociais e ambientais decorrentes do desabamento do Porto (MINISTÉRIO PÚBLICO FEDERAL, 2019).

Para além do contexto amazônico, mas também dentro da lógica comercial do mercado internacional, de exploração mineral no Brasil, cabe aqui citar que em março do ano de 2018, também a Empresa Anglo American registrou dois rompimentos no mineroduto Minas-Rio, gerando gigantescos vazamentos de polpa de minério no 
Estado de Minas Gerais. O primeiro sinistro acabou gerando o lançamento de 300 toneladas de minério de ferro no ribeirão de Santo Antônio do Grama (MG). O segundo rompimento lançou 647 toneladas de polpa de minério na Fazenda Córrego Grande, zona rural de Santo Antônio do Grama (MG), somando ao todo 947 toneladas de minério de ferro que foram despejadas na região. Devido as enormes dimensões dos desastres, bem como da geração de impactos socioambientais de grande magnitudes para aquela região, a Diretoria de Licenciamento Ambiental do Instituto Brasileiro do Meio Ambiente e dos Recursos Naturais Renováveis (IBAMA) determinou imediatamente a interrupção da operação do mineroduto, além cinco autos de infração que totalizam $R \$ 72,6$ milhões contra a mineradora (IBAMA, 2018).

Essas citações e reflexões, que demonstram que não é somente a região da Amazônia brasileira que sofre com esses grandes desastres socioambientais, decorrentes da atividade de extração mineral, mas que também outras regiões do Brasil são acometidas por esses sinistros, são de suma importância para uma tomada de consciência, de que esses desastres não são exclusivos de uma determinada região, mas sim, são frutos de uma notória falta do correto planejamento estratégico para as instalações e funcionamento desses grandes empreendimentos industriais no país.

Para Moraes (2017) ações intergovernamentais integradas podem aperfeiçoar gestões, para que elas atuem menos em ações paliativas de curto prazo, e mais em medidas estruturais e preventivas a médio e longo prazo. No cenário amapaense de conflitos que se estendem por grande parte do Estado, é imprescindível a reformatação das políticas de planejamento urbano-territoriais, que invistam no melhor planejamento das instalações industriais de mineração, na correta manutenção dessas estruturas, na prevenção e alertas de possíveis desastres socioambientais, decorrentes da atividade de extração mineral na região. 


\section{CONSIDERAÇÕES FINAIS}

Os desdobramentos do desabamento do Porto de Santana em 2013 mostram que o tempo socioambiental, do desastre sobre o Rio Amazonas é anterior ao evento ocorrido, porém foram agravadas em decorrência do mesmo. Só foi possível discutir as suas implicações e perspectivas, através de um breve retorno à história dos grandes empreendimentos instalados na região, em um Estado com dimensões relativamente pequenas, com infraestrutura pouco desenvolvida, mas com um potencial mineral de alto valor, que é muito cobiçado, tanto nacional quanto internacionalmente.

O desabamento do Porto trouxe à tona a intrínseca relação entre Serra do Navio, Pedra Branca do Amapari e Santana, bem como a importância desses municípios para o aquecimento da economia amapaense. Por outro lado, a queda do Porto de Santana também evidenciou problemas nas estruturas dessas instalações industriais, quem vêm sendo utilizadas há mais de cinco décadas, como as do Porto em questão, e as da Estrada de Ferro do Amapá, que interliga aqueles municípios.

A morte de trabalhadores, as demissões em massa, as dívidas trabalhistas, a luta por reparos aos danos causados ao meio ambiente e a sociedade que que sofre até hoje as consequências do desastre, as contaminações de rios e igarapés, com destaque ao Rio Amazonas, que foi diretamente atingido pelo desastre ocorrido, que pode ter sido afetado em seu caráter ambiental, em proporções incalculáveis, a paralisação das exportações, a forma de estocagem de minérios. Tudo isso são fatos que demonstram as debilidades das atividades de mineração industrial, instaladas no Estado do Amapá.

Portanto, conclui-se que são necessários mais investimentos em políticas de prevenção e instrumentos de fiscalização mais rigorosos para a implantação e funcionamento desses grandes projetos de mineração e seus desdobramentos, que possam mitigar os danos socioambientais decorrentes desde as suas instalações até 
possíveis desastres, tais como o ocorrido com o Porto de Santana no Estado do Amapá.

\section{REFERÊNCIAS}

BECK, Ulrich. A reinvenção da política: rumo a uma teoria da modernização reflexiva. In: BECK, U.; GIDDENS, A.; LASH, S. (Ed.). Modernização reflexiva: política, tradição e estética na ordem social moderna. São Paulo: Unifesp, 1997.

BRASIL, Agência nacional de mineração: Anuário Mineral Brasileiro. Substâncias Metálicas / Coord. Geral Osvaldo Barbosa Ferreira Filho; Equipe Técnica por Marina Dalla Costa et al.; - Brasília: ANM, 34 p. 2019.

BRITO, et al. Conflitos socioambientais no século XXI. PRACS: Revista de Humanidades, do Curso de Ciências Sociais da UNIFAP. Macapá, n. 4, p. 51-58, dez. 2011.

CANTO, Otávio. Mineração na Amazônia: assimetria, território e conflito socioabiental. NUMA. 2016.

CARVALHO, Isabel Cristina de Moura, STEIL, Carlos Alberto. Epistemologias ecológicas: delimitando um conceito. Revista Mana, v.20, n.1, Rio de Janeiro, p. 163183, 2014

CHAGAS, Marco. Antônio. Amapá: a mineração e o discurso da sustentabilidadede Augusto Antunes a Eike Batista. Garamond. 2013.

DIEGUES, Antônio Carlos, ARRUDA, Rinaldo Sérgio Vieira. Os saberes tradicionais e biodiversidade no Brasil. São Paulo: NUPAUB-USP: MMA, p. 1-71, 2000.

GIDDENS, Anthony. As consequências da modernidade. São Paulo: UNESP, 1991. 
GILBERT, Claud. Studying disaster: changes in the main conceptual tools. In: QUARANTELLI, E. (Ed.). What is a disaster? Perspectives on the question. Routledge: London and New York; p. 11-18, 1998.

IBAMA. Instituto Brasileiro do Meio Ambiente e dos Recursos Naturais Renováveis. Ibama multa Anglo American em R $\mathbf{7 2}$ milhões por vazamentos no mineroduto Minas-Rio em MG. Brasília, 2018.

IBGE, INSTITUTO BRASILEIRO DE GEOGRAFIA E ESTAtísticA. Censo demográfico de 2010.

, INSTITUTO BRASILEIRO DE GEOGRAFIA E ESTATístICA. Atlas - Perfil das cidades brasileiras. 2019.

LIBISZEWSKI, Stephan. What is a Environmental Conflict? 1992.

MARCHEZINI, Victor. Dos desastres da natureza à natureza dos desastres. N Valêncio et al. (Orgs) Sociologia dos Desastres: construção, interfaces e perspectivas no Brasil. São Carlos, Rima Editora, p. 48-57, 2009.

As ciências sociais nos desastres: um campo de estudo em construção. Revista Brasileira de Informação Bibliográfica, número 83-2017. São Paulo, p 43-72. 2018.

MENDES, José Manuel; ARAÚLO, Pedro. Risco, catástrofes e a questão das vítimas, E-cadernos ces [Online], 25 | 2016, colocado online no dia 15 Junho 2016. DOI: 10.4000/eces.2029.

MARÍTIMO, Museu de Pesquisa. A explosão de Halifax. 2018.

MINISTÉRIO PÚBLICO FEDERAL. Anglo American firma acordo para indenizar municípios em 47 milhões pelo desabamento do Porto de Santana (AP). 2019. 
MORAIS, Paulo Dias. O Amapá em perspectiva: municípios do Amapá. Gráfica. 2011.

MORAIS, Paulo Dias; MORAIS, Jurandir dias. Geografia do Amapá Gráfica. 2011.

MORAES, Marcela. (2017). As ocupações irregulares e suas relações com as áreas de risco no espaço urbano de Cariacica-ES: o caso de Porto de Santana. Dissertação de mestrado. UNIVERSIDADE FEDERAL DO ESPÍRITO SANTO. CENTRO DE CIÊNCIAS HUMANAS E NATURAIS PROGRAMA DE PÓSGRADUAÇÃO EM GEOGRAFIA. 133 p. 2017.

NAFES, Seles. Sem nunca ter sido usado, Porto de $\mathbf{4 8 4}$ milhões de reais afunda no Rio Amazonas. 2019.

OLIVER-SMITH, Anthony. Disastres y Sociedade. Revista Semestral de La Red de Estudios Sociales en Prevencion de Desastres En America Latina. 2-1.0-nov-19-2001.

RIBEIRO, Adalberto Carvalho; SILVA, Rubens Pinheiro. Aspectos institucionais e urbanos para o desenvolvimento local do município de Pedra Branca do Amapari/Amapá. PRACS: Revista de Humanidades do Curso de Ciências Sociais da UNIFAP Macapá, n. 3, p. 19-32, Dez. 2010.

RIPLEY, Amanda. Impensável: Como e por que as pessoas sobrevivem a desastres. Ed. Globo, 2008.

SOUZA, Keulle Oliveira da. et al. Exploração mineral na Amazônia brasileira: Relações de trabalho e migração interna no Município de Pedra Branca do AmapariAP. Revista Científica Multidisciplinar Núcleo do Conhecimento. Ano 04, Ed. 12, Vol. 08, pp. 05-28. Dez. 2019a. ISSN: 2448-0959

SOUZA, Keulle Oliveira da. et al. Alterações socioambientais e na saúde decorrentes da implantação de projetos de mineração em Barcarena-PA: $O$ desenvolvimento e suas contradições na Amazônia, Brasil. Revista Científica Multidisciplinar Núcleo 
do Conhecimento. Ano 04, Ed. 12, Vol. 08, pp. 29-39. Dez. de 2019b. ISSN: 24480959

SOROKIN, Pitirim, Alexandrovich. Man and society in calamity: the effects of war, revolution, famine, pestilence upon human mind, behavior, social organization and cultural life. Nova York: E.P. Dutton and Company, 1942.

QUARANTELLI, Enrico Louis. What is a disaster? Perspectives on the question. Routledge: London and New York, 1998.

QUARANTELLI, Enrico Louis. Uma agenda de pesquisa do século 21 em Ciências Sociais para os desastres: questões teóricas, metodológicas e empíricas, e suas implementações no campo profissional. 2005 (tradução Raquel Brigatte). Revista o Social em Questão. Ano XVIII no 33. 2015.

TOSTES, José Alberto. Questões urbanas, pobreza e falência das cidades do Estado do Amapá. Disponível em: https:/josealbertostes.blogspot.com/2015/03/questoes-urbanas-pobreza-e-falenciadas.html Acesso em 10 de dezembro de 2019

VALÊNCIO, Arthur; VALÊNCIO, Norma Felicidade Lopes da Silva. A Cobertura jornalística sobre desastres no Brasil: dimensões sociopolíticas marginalizadas no debate público. Anuário Electrónico de Estudios em Comunicación Social "Disertaciones". 10(2), p. 165-186. 2017.

VALÊNCIO, Norma Felicidade Lopes da Silva. Da morte de Quimera à fuga de Pégaso: a importância da interpretação sociológica na análise no fenômeno denominado desastre. N Valêncio et al. (Orgs) Sociologia dos Desastres: construção, interfaces e perspectivas no Brasil. São Carlos, Rima Editora, p. 1-19. 2009.

Enviado: Dezembro, 2019.

Aprovado: Dezembro, 2019. 